\title{
A PERSPECTIVA ESTÉTICA E EXPRESSIVA NA ESCOLA: ARTICULANDO CONCEITOS DA PSICOLOGIA SÓCIO-HISTÓRICA
}

\author{
Denise de Camargo \\ Yara Lúcia Mazziotti Bulgacov
}

\begin{abstract}
RESUMO. Este artigo apresenta uma reflexão sobre as contribuições do campo das artes para a educação. Parte-se da constatação de que em nosso cotidiano as relações entre as pessoas são cada vez mais orientadas por razões econômicas e instrumentais. Compreende-se a escola como invadida por esta lógica e assim perde-se um espaço fundamental de interrogação, o qual é necessário para nos descobrirmos como seres autônomos, singulares e em movimento. Entende-se que a estética pode vir a ser um instrumento para a educação dos aspectos sensíveis, levando-nos a descobrir formas até então inusitadas de perceber o mundo. Dimensões das atividades artísticas - estética e expressiva - são conceituadas e passa-se, em seguida, a defender, a partir dos pressupostos da psicologia sócio-histórica, que essas dimensões contribuem para a expressão e organização da emoção e da imaginação. Finalmente, o artigo discute a proposta de oficinas, espaços de ação e reflexão, um fazer próximo à arte.
\end{abstract}

Palavras-chave: estética, psicologia sócio-histórica, atividade expressiva na escola.

\section{THE AESTHETIC AND EXPRESSIVE PERSPECTIVE IN SCHOOL: ORGANIZING SOCIO- HISTORICAL PSYCHOLOGICAL CONCEPTS}

\begin{abstract}
Contributions of Arts on education are provided. Day-to-day relationships between people are more and more guided by economic and functional motives. The school institution has also been invaded by this logic stance and a fundamental space for interrogation has been lost. This has always been necessary to discover ourselves as autonomous, singular and non-static beings. Aesthetics may become an instrument to educate sensitiveness and may lead us to discover a world which has been unknown up to the present. Artistic activities - aesthetic and expressive - are defined whilst these factors contribute towards the expression and the organization of emotion and imagination as from the standpoint of sociohistoric psychology. Workshops as spaces for activities and reflections, or rather, an activity close to Art, are also investigated.
\end{abstract} Key words: Aesthetic, socio-historic psychology, aesthetic perspectives in school.

\section{PERSPECTIVA ESTÉTICA Y EXPRESIVA EN LA ESCUELA: ARTICULANDO CONCEPTOS DE LA PSICOLOGÍA SOCIO-HISTÓRICA}

\begin{abstract}
RESUMEN. El artículo presenta una reflexión de las contribuciones del campo de las artes para la educación. Se parte de la constatación de que en nuestro cotidiano las relaciones entre las personas son cada vez más orientadas por razones económicas e instrumentales. Se comprende la Escuela también como invadida por esta lógica y, de ese modo, se pierde un espacio fundamental de interrogación; nos hace falta descubrirnos como seres autónomos, singulares y en movimiento. Se entiende que la estética puede venir a ser un instrumento para la educación de lo sensible, llevándonos a descubrir formas hasta entonces inusitadas de percibir el mundo. Se conceptúa estética y actividad expresiva, se pasa, en seguida, a defender, a partir de las premisas de la psicología socio-histórica, como esas dimensiones contribuyen para la expresión y organización de la emoción y de la imaginación. Por fin el artículo presenta ejemplos de actividades.
\end{abstract}

Palabras-clave: Estética, psicología socio-histórica, perspectiva estética en la escuela.

\footnotetext{
* Docente aposentada da Universidade Federal do Paraná. Pesquisadora na Linha de Organizações, Empreendedorismo e Inovação.

\# Professora e pesquisadora do Mestrado em Administração da Universidade Positivo. Professora Sênior vinculada ao Mestrado em Administração da Universidade Federal do Paraná-UFPR.
} 
O que é que tem caracterizado a rede de relações que constitui nossa cultura? Qual modo de relação tem predominado? Podemos observar o mundo moderno orientado por uma razão calculante, uma razão instrumental que domina nossa capacidade intelectiva, a qual é orientada para os aspectos econômicos e privilegia a perspectiva quantitativa dos fenômenos. Habermas (1987) nos alerta de que esta racionalidade instrumental, dirigida a fins com sua própria estrutura de controle e dominação, permeia, inclusive, o mundo da vida, o espaço do homem, o espaço de suas necessidades e desejos.

Duarte Jr. (2001) esclarece como essa lógica instrumental tem transformado nossas mais cotidianas atividades e desestimulado qualquer refinamento de nossos sentidos, fazendo-os regredir até níveis grosseiros. Este autor ilustra esta realidade afirmando:

[...] nossas casas não expressam mais afeto e aconchego, temerosos e apressadamente nossos passos cruzam os perigosos espaços de cidades poluídas, nossas conversas são estritamente profissionais, nossa alimentação feita às pressas e de modo automático, entopem-nos de alimentos insossos, contaminados e modificados industrialmente, nossas mãos já não manipulam a natureza, espigões de concreto ocultam os horizontes, os odores que sentimos vêm dos esgotos, de chaminés de fábrica e de depósitos de lixo, e em meio a tudo isto, trabalhamos de forma mecânica e desprazerosa até o stress (Duarte Jr., 2001, p.18).

Não bastassem essas relações "insensíveis" com as atividades, nossas relações com os outros também se deformam: tomamos o outro como objeto, tomamos o outro como um fim. No campo da ciência o outro se torna objeto de nosso saber, na filosofia o outro é objeto de nossa reflexão e, em nosso cotidiano, objeto de nosso interesse. Assim, a partir dessa lógica construímos e "vivemos" este mundo.

Como era de esperar, essa realidade instrumental, contraditoriamente, também invade o cotidiano de nossas escolas. Machado (1994, p. 28), ao comentar um texto de Paz (1977), mostra, de forma incisiva, essa situação. Indaga de que maneira o nosso sistema educacional permite ao jovem exercer sua "consciência interrogante". Julga redundância esclarecer quanto uma criança, desde mais ou menos sete anos de idade, já está "formada" pelos padrões do certo e do errado, quanto suas possibilidades de perguntar sobre $o$ "que pode ser" estão enquadradas em regras preestabelecidas na escola. A criança, daí para frente, só busca guiar-se pelo que "parece estar de acordo" com o mundo dos adultos, pelas exigências do "vencer na vida". Para a autora, o momento da adolescência é crucial para que a escola preencha de significados as indagações do adolescente frente a seu próprio ser. Acredita que a escola deva dar espaço para a revelação da "consciência interrogante" do adolescente. A escola deveria, por exemplo, propiciar condições para que o adolescente pudesse descobrir sua consciência, uma consciência percebida e sentida como algo particular, intransferível, como diz Paz (1977). É preciso que ao adolescente seja permitido apoderar-se do único ser que ele é, das suas aptidões, seus sonhos, angústias e indagações. É preciso, acrescenta Machado (1994), ter um espaço que me permita, se tenho quinze anos, confrontar-me com quem sou, com minha individualidade, no momento em que a descubro como minha. É preciso que me seja permitido ouvir minha voz que diz, dentro de mim, o que eu poderia ser ou gostaria de ser, e não uma voz que me diz o tempo todo o que fazer.

Estamos constatando que nosso ambiente escolar vem perdendo um espaço fundamental para nos tornarmos humanos, de nos descobrirmos como seres únicos e em movimento. É um ambiente que não legitima nem a interrogação, nem a possibilidade, que não incentiva a individualidade nem a construção de nossa autonomia e, conseqüentemente, nem o respeito pela autonomia do outro.

A preocupação com as experiências de crianças e jovens na escola tem sido tema de estudo de um grande número de educadores e pesquisadores brasileiros. Entre as reflexões sobre a escola em sua interface com a estética, que é o foco de nossa reflexão, destacamos principalmente os trabalhos de Barbosa (2002), Duarte Jr. (2001), Zanella, Da Ros, França e Reis (2004), e do Instituto Arte na Escola, da Fundação Iochpe, a qual dispõe de uma proposta sobre o ensino da arte fundamentada teoricamente. $\mathrm{O}$ Instituto declara ter como missão: “... incentivar e qualificar o ensino da arte e como premissa que a arte, enquanto objeto do saber, desenvolve no aluno habilidade perceptiva, capacidade reflexiva e formação de consciência crítica, não se limitando à auto-expressão e à criatividade" (http://www.artenaescola.org.br/2007).

Este artigo tem como principal objetivo trazer para a discussão sobre a estética na educação os conceitos e preocupações da psicologia sóciohistórica. Pretendemos, aqui, estabelecer um diálogo com o professor, explorando algumas contribuições possíveis no campo das artes para a educação, na medida em que a entendemos como constituinte do ser humano e, ao mesmo tempo, de forma mais específica, trabalharmos algumas condições para a efetiva 
implementação de uma concepção de aprendizagem que tenha sentido para o jovem e que consista de um conjunto de atividades criativas.

Num primeiro momento, conceituamos as duas perspectivas do campo das artes (estética e expressiva) que foram eleitas para esta reflexão ${ }^{1}$. Nas seções seguintes, argumentamos sobre a importância dessas dimensões na construção da emoção e da imaginação. Finalmente, na última seção, propomos algumas atividades $^{2}$ que, a nosso ver, viabilizam de algum modo o alcance de alguns dos princípios acima enunciados e que o professor poderia utilizar em sala de aula.

\section{AS PERSPECTIVAS ESTÉTICA E EXPRESSIVA NO CAMPO DAS ARTES}

Qual a promessa do campo das artes para a educação? Sanches Vasquez (1978) afirma que o artista, ao refletir sobre a realidade, revela a realidade humana do real.

Perguntamos: quais aspectos da relação do artista com o mundo, ou mesmo com a obra, permitem que essa humanidade seja revelada? Entendemos que a "perspectiva estética" e a "perspectiva expressiva das atividades artísticas" fazem a diferença, por isso as elegemos para esta reflexão.

Em primeiro lugar é preciso deixar bem claro que adotar uma perspectiva estética na educação não significa trabalharmos necessariamente para a formação de artistas. Significa, antes de tudo, construirmos uma educação que tenha a arte, ou mesmo as atividades expressivas da arte, como aliadas na relação ensinar-aprender. Por outro lado, não se trata, igualmente, de transformar a estética em disciplina formal do currículo escolar, quer essa disciplina seja denominada como "Educação Artística" ou "Estética Filosófica", quer estas duas constituam disciplinas isoladas. Aprisionar a estética a qualquer disciplina ou a qualquer instituição - escola ou museu - é destruir o próprio sentido da estética, qual seja, a expressão de flexibilidade, sutileza, diversidade de formas e vivências.

$\mathrm{O}$ que é que significaria concretamente, para o professor, tomar como princípio orientador de sua ação na escola não aprisionar a estética em uma disciplina? Isto não seria uma aparente contradição, uma vez que toda programação de aprendizagem está

Não vamos discutir a arte em si, mas trazer da arte as dimensões estética e expressiva para o cotidiano da Escola.

2 As atividades trazidas são exemplos e não pretendemos elaborar uma proposta curricular de arte-educação. formalmente embutida em disciplinas? Como poderá o professor trabalhar essa questão fora dos conteúdos formais das disciplinas? Retomaremos essa questão mais adiante.

Outra característica da estética é que ela também não está a serviço da moral. O que isto quer dizer? Quer dizer que quando tomamos a linguagem das artes, percebemos que ela é uma linguagem aberta, complexa, e que condensa uma multiplicidade de significados, possibilitando uma diversidade de interpretações (Goodman, 1995). Veremos a seguir que, uma vez que se abre para uma multiplicidade de significados, a linguagem das artes tem uma implicação direta para a questão da moralidade que queremos apontar. Tomemos um exemplo bastante ilustrativo dessa dimensão, dado por Vigotski (2001). Ao comentar a fábula A Cigarra e a Formiga, a qual, em tese, deveria transmitir a ética do trabalho, Vigotski destaca que, contraditoriamente, a simpatia das crianças é direcionada para a cigarra, que, despreocupada e poética, passou o verão inteiro cantando, enquanto a formiga lhes parece sombria, enfadonha e avarenta.

Aqui convidamos o professor a uma reflexão. Quantas vezes utilizamos o certo e o errado de forma absoluta? A formiga é a certa, pois trabalha. A cigarra é a errada, pois canta. Não estamos contribuindo aí para o grande fosso entre trabalho e lazer, por exemplo? Criamos, muitas vezes, uma realidade fechada, uma realidade sem possibilidades. Musil (1989) nos ensina que, se existe o senso de realidade, deve existir o senso de possibilidade. "Senso de possibilidade pode ser definido como a capacidade de pensar tudo aquilo que poderia ser, e não julgar que aquilo que é seja mais importante daquilo que não é" (Musil, 1989, p. 24). Quantas vezes nós, como professores, destruímos essa tensão criativa, quando claramente separamos pessoas sonhadoras de um lado e pessoas realistas de outro? Quantas vezes impedimos um vôo, um desejo de construção, uma utopia de alguém que, como nos diz Musil (1989), não teme a realidade? Pois, afinal, o que é a realidade senão uma possibilidade que se concretizou? O que é a possibilidade senão uma idéia, uma realidade não nascida?

Entendemos que, por meio da aproximação com as artes, a estética pode vir a ser um instrumento para a educação do sensível, levando-nos a descobrir formas até então inusitadas de perceber o mundo. Por meio da experiência estética o homem desenvolve a capacidade sensível, a percepção, e constrói um olhar que o incentiva a perceber a realidade de diversos ângulos, sob diversos aspectos. 
Para Gagliard (1990), a estética é uma "forma de conhecimento sensorial", em contraposição ao conhecimento intelectual. É uma "forma expressiva de ação", desinteressada e sem uma finalidade instrumental específica. É uma "forma de comunicação" diferente da comunicação oral e é caracterizada pela possibilidade de partilhar sentimentos e conhecimentos tácitos, os quais não podem ser explicados ou codificados. Enfim, a estética é uma forma de apreendermos a realidade moldada por nossas experiências sensoriais. A estética está associada ao belo, mas não exclusivamente a ele. Está ligada, da mesma forma, à unidade, à integridade e à harmonia, atributos presentes nas obras de arte. ${ }^{3}$

A sensibilidade estética surge nesse processo de percepção dos objetos que transcende a dimensão utilitária direta e ultrapassa uma atitude unívoca diante da realidade. Na relação estética o sujeito entra em contato com o objeto mediante a totalidade de sua riqueza humana, não apenas sensível, mas também intelectiva e afetiva. Os fenômenos naturais só se tornam estéticos quando adquirem uma significação social e humana.

Criando novos objetos, descobrindo novas propriedades e qualidades deles, bem como novas relações entre as coisas, o homem ampliou consideravelmente, graças à sua atividade prática, material, o horizonte dos sentidos e enriqueceu e elevou a consciência sensível até o ponto de converter-se em expressão das forças essenciais do ser humano. A sensibilidade estética é, por um lado, uma forma específica da sensibilidade humana, e, por outro lado, é uma forma superior dela, enquanto expressa - em toda a sua riqueza e plenitude - a verdadeira relação humana com o objeto como configuração das forças essenciais humanas nele objetivadas (Sanches Vasquez, 1978, p. 86).

Esperamos ter explicado a importância da estética para a construção de relações mais gratificantes, de relações em que não se coloca o utilitário como denominador, mas de relações que acolhem a beleza, o múltiplo, o diferente. É importante sublinhar para o professor que essas relações não se restringem à sala

3 Existem, a nosso ver, outras concepções de estética, incluindo o feio, por exemplo, e não necessariamente o harmônico. Contudo, elegemos para reflexão, neste momento, essas dimensões, as quais, embora não-exclusivas, podem vir a contribuir para uma educação mais integral. Para um aprofundamento da dimensão estética do feio, ler Sanches Vásquez (1999), Capítulo III: As aventuras do feio. de aula, devendo se dar também no âmbito geral das relações escolares.

Tomemos a outra dimensão das artes a respeito da qual queremos refletir: a "dimensão expressiva" das atividades artísticas. Compreendemos como dimensão expressiva a característica das atividades artísticas que possibilita a auto-expressão, entendida como necessidade do indivíduo de comunicar seus pensamentos e emoções a outros indivíduos. Queremos enfatizar ao professor a importância dessa atividade para o desenvolvimento do aluno. Como pressupõe um dos princípios da psicologia sóciohistórica, é na atividade que o homem se constrói. A atividade a ser produzida não precisa, necessariamente, ser artística no sentido dos critérios artísticos. Nominamos atividades expressivas aquelas atividades que são próprias das artes (desenho, pintura, fotografia e escultura, entre outras), mas não respondem a seus critérios, ou seja, são utilizadas como estratégias de desenvolvimento, estratégias de auto-expressão, da construção de si.

Conceituadas as duas dimensões das atividades artísticas - estética e expressiva -, passaremos a defender, a partir dos pressupostos da psicologia sócio-histórica, como essas dimensões contribuem para a expressão e organização, tanto da emoção, como da imaginação. Isso ajudará na compreensão de como podemos criar em nossas escolas aquelas condições que se incompatibilizem com relações humanas mecânicas e empobrecidas, às quais já fizemos referência neste ensaio.

\section{A DIMENSÃO ESTÉTICA E EXPRESSIVA DAS ARTES NA CONSTRUÇÃO DA EMOÇÃO}

Muitos conceitos de arte têm sido ensaiados. O difícil é obtermos um consenso entre eles. São muitos e privilegiam dimensões diferentes. Uma das conceituações mais usuais da arte é entendê-la como criação de uma "forma expressiva de sentimento, de emoção humana". O primeiro aspecto que sobressai dessa conceituação é sua característica de criação. Arte é sempre criação. Nesse conceito a ênfase está na expressão dos afetos. No entanto, para que uma obra seja identificada como arte, outras dimensões importantes não podem ser esquecidas. Segundo Deleuze e Guattari (2001), “o artista (...) excede os estados perceptivos e as passagens afetivas do vivido. É um vidente, alguém que se torna” (p. 222). Para esses autores:

A arte é a linguagem das sensações, que faz entrar nas palavras, nas cores, nos sons ou 
nas pedras. A arte não tem opinião. A arte desfaz a tríplice organização das percepções, afecções e opiniões, que substitui por um monumento composto de perceptos, de afectos e de blocos de sensações que fazem as vezes de linguagem (Deleuze \& Guattari, 2001, p. 228).

Conscientes da dificuldade de trazer um conceito que apreenda a complexidade da arte e principalmente do processo de criação, relembramos aqui a necessidade de auto-expressão de sentimentos/emoções para o desenvolvimento integral do ser humano. Considerando que o ser humano tem necessidade de comunicar seus sentimentos e emoções, é a arte um meio por excelência para atender a essa necessidade. A arte pode vir a preencher essa função.

Como se dá essa relação da arte com as emoções? Vigotski (2001) denomina "percepção estética" aquilo que uma pessoa experimenta diante de uma obra de arte. Para o teórico, a percepção estética caracteriza-se por ser uma vivência ativa e rica em momentos afetivos por parte da pessoa que frui a obra. As pessoas constroem e criam por meio dos sentidos e significados que imprimem à obra.

Por outro lado, arte não propicia apenas a expressão dos sentimentos. Diz-nos Vigotski (citado por Paez \& Adrián, 1993) que a arte canaliza um aspecto de nossa psicologia que não encontra saída em nosso cotidiano. Ela resolve tensões de nossa relação com o meio. A arte, diferentemente da emoção direta, não engendra uma ação. Por exemplo, uma reação direta ao medo de um rato faz o indivíduo correr. $\mathrm{O}$ medo gerado pela arte - em uma cena no teatro, no cinema - gera retenção da ação, rompe com o equilíbrio interno, faz reviver uma emoção, aclara reações emocionais, torna a sensibilidade mais aguda, funde emoções, promove a superação dessas emoções.

Entendemos que as atividades expressivas das artes propiciam o que Rimé (1993) denomina de reevocação das emoções. Partindo da constatação de que o ser humano tem a necessidade de partilhar suas emoções com os outros, de articular sua experiência privada, o autor afirma que existem vários meios pelos quais o ser humano partilha as emoções: "as palavras, as frases pronunciadas, as páginas escritas, as notas de música ou a pintura são como várias tentativas de desdobramento da emoção" (Rimé, 1993, p. 277). Mesmo que essas produções nunca sejam lidas ou vistas, percebe-se que o indivíduo tem necessidade de organizar sua experiência emocional no espaço e no tempo.

A esse movimento de organização da experiência emocional no espaço e no tempo, propiciando sentir novamente determinada emoção, dá-se o nome de reevocação das emoções. "Quando sujeitos são convidados a evocar em imagens mentais lembranças ligadas a um determinado estado emocional, as manifestações subjetivas e psicológicas próprias a esse estado emocional tendem a se reinstalar neles" (Rimé, 1993, p. 279). Assim, a reevocação não é uma simples ruminação dos sentimentos, mas uma reorganização cognitiva que leva o indivíduo a sentir e ressignificar seus estados emocionais.

Através das atividades expressivas das artes, o sujeito está promovendo a ressignificação e reorganização de seu estado emocional; ou seja, ele "re-sente" a emoção e lhe confere um novo significado (ressentir, aqui, no sentido de sentir novamente, e não como ruminação de sentimentos). "Reevocar a emoção é, em certa medida pelo menos, revivê-la" (Rimé, 1993, p. 279).

Ao executarem atividades expressivas os alunos estariam revivendo e reevocando as suas próprias emoções. Rimé (1993) afirma:

É evidente que os indivíduos não poderiam prosseguir a empresa de reevocação de suas experiências emocionais se não tivessem diante de si parceiros, um público disposto a se interessar por este tipo de evocação. Ora, a vida social está cheia de exemplos manifestando o interesse muito especial das pessoas pela audição, a leitura ou a visão de acontecimentos emocionais. Eles se revelam dispostos a se informar sobre as emoções que atingiram os outros. [...] Assistir à evocação da experiência emocional de outrem é, em um nível incipiente pelo menos, viver essa experiência (p. 295).

Rimé (1993) discute a diferença entre a experiência emocional que atinge o indivíduo quando ele está no centro (ou quando ele é o centro) e uma situação que o atinge a partir da evocação da emoção do outro. "O que propõem as situações como o teatro, o cinema, o romance, as conversas ou as confidências, é, igualmente, da experiência emocional direta, uma emoção social e lingüisticamente estruturada" (p. 296)

O motivo de se procurar a reevocação emocional do outro é que esta é uma emoção social e lingüisticamente estruturada, uma experiência emocional já organizada. Dessa forma, aprende-se com o outro como reagir e interagir com as emoções. É uma espécie de antecipação, o ensaio de um momento. Assim, em face do relato do outro, o sujeito teria instrumentos para organizar a emoção espelhando-se na organização que o outro fez. Ao tomar contato com as experiências emocionais do 
outro, o sujeito está se apropriando de uma experiência emocional estruturada, podendo, assim, antecipar e ensaiar essas vivências emocionais.

\section{A DIMENSÃO ESTÉTICA E EXPRESSIVA DAS ATIVIDADES ARTÍSTICAS NA CONSTRUÇÃO DA IMAGINAÇÃO}

Arnheim (1969) alerta-nos para como os nossos olhos foram reduzidos a instrumentos para identificar e medir, e assim sofremos de uma carência de idéias traduzíveis em imagens, o que nos predispõe a certa incapacidade de descobrir significados naquilo que vemos. Ele denuncia a prisão da nossa imaginação, comprometida pelo condicionamento racional do nosso olhar, por uma lógica positiva de assimilação e reprodução dominante da sociedade ocidental.

Da mesma forma, a escola tem cumprido um forte papel na domesticação do imaginário, como já ressaltaram, em 1964, os estudos de Gilbert Durant, tema retomado por Bruno Duborgel no livro Imaginário e Pedagogia (Durant, 1964; Duborgel, 1992).

Entendemos, como Machado (1994), que a escola deve ser um lugar em que se possa exercitar a imaginação, estando entre os seus muitos sentidos aquele de permitir ao indivíduo perguntar-se o que pode vir a ser, livre das amarras do certo ou do errado. Nesse sentido, o "real" deixa de ser rígido, preestabelecido para sempre, e passa a ser algo que se pode olhar a partir de vários ângulos, para encontrar a melhor forma de compreendê-lo.

A imaginação contém o atributo da elasticidade e leva à atividade criadora, a qual combina a projeção do futuro para modificar o presente e possibilita a criação artística, científica, técnica e sentimental. Reproduz, reelabora e recria, a partir da realidade, com isso criando outra realidade. Cria significados, recria idéias e conceitos, rompe com o espaço e com o tempo.

Partimos do pressuposto de que a capacidade de imaginar é o elemento principal para a constituição de um sujeito autônomo, criativo e livre, uma capacidade que pode ser desenvolvida, dentre outras formas, com a adoção de atividades expressivas no espaço de liberdade da escola.

Imaginar algo significa transformação, a criação de algo novo. Para poder transformar a realidade, na prática, é preciso saber transformá-la mentalmente, e esta exigência é cumprida pela imaginação. Segundo Vigotski (1990), toda e qualquer atividade humana que não se limite a reproduzir fatos ou impressões vividas, mas que produza novas imagens e novas ações, pertence à função criadora ou imaginadora: se a atividade humana se reduzisse a repetir o passado, o homem seria um ser incapaz de se adaptar a um amanhã diferente. É precisamente a atividade imaginadora do homem que faz dele um ser projetado para o futuro. Aí reside a importância da imaginação: através dela o homem torna-se um ser capaz de projetar o futuro, de redimensionar sua história.

As novas formas de ver, ouvir e sentir trazidas pela arte impulsionam à criação na ciência e na própria adaptação do homem aos desafios do cotidiano. Como nos exemplifica Goodman (1995), assim como o estudante de ciência necessita saber ler inteligentemente, saber calcular e ter certa experiência da inferência, da experimentação e da motivação que provoca a investigação e o descobrimento, o estudante sério de uma arte está, do mesmo modo, capacitado para ver e ouvir inteligentemente, bem como para ter experiências de percepção ativa, de imaginação criativa e de motivação, as quais provocam novas idéias e invenções nas artes.

\section{COMO AS PERSPECTIVAS ESTÉTICA E EXPRESSIVA PODEM SE OBJETIVAR NO COTIDIANO DA ESCOLA}

O que significariam, concretamente, essas dimensões estéticas e expressivas no cotidiano da escola? Entendemos que o processo de aprendizagem não fica restrito à sala de aula: ele passa, sobretudo, pelas relações interpessoais.

A aprendizagem ocorre, de modo particular, quando algo faz sentido para o homem. Para que ocorra, ela deve estar vinculada às experiências, interesses, emoções e valores. Duarte Jr. (1994) conceitua: "Aprender é um processo que mobiliza tanto os significados, os símbolos, quanto os sentimentos, as experiências a que eles se referem" (p. 25).

A aprendizagem é um processo ativo por parte do sujeito, podendo ser compreendida como um sistema de atividades cuja realização conduz a pessoa a novos conhecimentos, novos hábitos, em que os conhecimentos e hábitos anteriores adquirem novas qualidades. Reflitamos brevemente sobre esta conceituação: aprendizagem como um processo ativo por parte do sujeito e como um conjunto de atividades. Pensemos, primeiramente, a respeito do conceito de atividade.

A atividade desempenha "a função de situar o homem na realidade objetiva e de transformar esta em uma forma de subjetividade" (Leontiev, 1978, p. 74). A atividade, por natureza, é social. Toda atividade humana, qualquer que seja a estrutura que tome, é sempre uma atividade inserida no sistema de relações sociais. Ela se realiza por meio de instrumentos que 
são sociais e se desenvolve mediante a cooperação e a comunicação dos homens. É por meio da atividade que o homem se apropria da prática histórico-social, da experiência da humanidade.

Nessa perspectiva, compreendemos a educação e o ensino como tipos organizados de atividade conjunta - professores e alunos - que possibilitam a assimilação, pelas gerações mais novas, da experiência das gerações anteriores.

A aprendizagem é uma atividade e, como tal, está associada aos sentimentos. A atividade está associada a uma classe particular de impressões psíquicas: as emoções e os sentimentos (Leontiev, 1978).

Vigotski (1990) estabeleceu dois tipos básicos de atividade: a atividade reprodutora e a atividade criadora. A primeira está vinculada à memória e caracteriza-se pela reprodução de normas de conduta já criadas e elaboradas. A segunda compreende as realizações humanas criadoras ou combinatórias de algo novo, sejam novas imagens sejam novas ações. Com os elementos das experiências passadas, o homem é capaz de reelaborar e criar novas ações, imagens, normas, bem como de planejar. "É precisamente a atividade criadora do homem o que faz dele um ser projetado para o futuro, um ser que contribui a criar e que modifica seu presente" (Vigotski, 1990, p. 9).

O processo de aprendizagem não é apenas uma atividade reprodutora. Na medida em que o novo deve se integrar aos conteúdos anteriores aprendidos - o que só acontece com a participação ativa do aluno - a aprendizagem supõe também uma atividade criativa.

Não sendo reduzida a atividade reprodutora e imitativa, a aprendizagem torna-se uma atividade de enorme complexidade que se vincula à imaginação e à afetividade. A aprendizagem concebida como atividade criadora supõe mudança na proposta pedagógica: mudança de uma prática que nega, reprime, exclui, censura, subordina, marginaliza a imaginação e a vida afetiva dos alunos, para uma prática que transforme a imaginação e a afetividade em ações mobilizadoras da atividade.

"Como, então, associar os conceitos até então desenvolvidos?", devem estar indagando os professores. De que modo seria possível, no contexto escolar e suas prescrições, implementar essas atividades criativas que ajudariam os jovens a construir relações mais humanas e menos instrumentais? Como trazer a experiência estética e expressiva para o cotidiano da escola?

Em primeiro lugar, devemos ter claro que não se trata de gerenciar a imaginação da criança, selecionando o que se deve oferecer a ela. Também não se trata de deixá-la à mercê "de extrair das próprias reservas os recursos de seu desenvolvimento" (Duborgel, 1992, p. 298), em uma concepção espontânea. Trata-se, entendemos, de colocar o aluno diante de uma multiplicidade de objetos, imagens, mitologias, lendas, narrativas, contos, poemas. Como sugere Duborgel (1992), trata-se de ter presente uma pinacoteca pluralista de obras para conhecer, reconhecer, devanear, amar e questionar; a pinacoteca para ser um espaço do saber, do conhecer, para desenvolver no aluno a habilidade perceptiva, a capacidade reflexiva e a formação de consciência crítica.

Para combater a visão dominante de que a arte é apenas entretenimento ou uma atividade acessível apenas a uma elite, propomos a utilização de "oficinas de atividades expressivas" no cotidiano escolar.

A concepção de oficina se sustenta no fazer, um fazer próximo à arte. $\mathrm{O}$ jeito de fazer arte possibilita a expressão e a construção do sujeito que faz. O fazer realiza-se no produto. Produto e produtor se transformam. O produtor se reconhece no produto. Produto e produtor se transformam mutuamente.

Importante ressaltar aqui que quando falamos de oficina nós o fazemos para marcar o fazer e nos distanciarmos daquela escola que imobiliza o aluno na ação e no pensamento. Quando identificamos o fazer próximo à arte é para também marcar que o sujeito que faz está presente no fazer, com suas vivências, suas percepções, seus afetos, seus conceitos e sua visão de mundo. Quando nos aproximamos do processo de criação do artista verificamos como esse é um processo que implica projeto, pesquisa conceitual e de materiais, e muita reflexão. O fazer-arte é um fazer pensante.

O produto faz-nos conhecer o produtor, sua identidade. Devemos dar aos alunos condições para que eles desenvolvam seus próprios produtos e construam, por meio do fazer expressivo, sua própria identidade, e não apenas reproduzam a identidade do professor, numa condição que tomamos como alienação. Entendemos que, por via das oficinas de atividades expressivas, podemos interromper a alienação do objeto de trabalho, na medida em que serão dadas ao aluno condições de decidir, conceber o projeto de trabalho, eleger o método por meio do qual conduzirá o seu trabalho - um trabalho seu, que refletirá suas escolhas, seus métodos, etapas, ritmos, gestos e, portanto, sua subjetividade, sua identidade em transformação.

Por exemplo, as oficinas de trabalho artístico dariam condições aos alunos de ter contato com artistas, visitá-los em seus locais de trabalho, 
descrever seu trabalho, analisar os incidentes críticos do cotidiano da criação. Nas oficinas de poesia, eles poderiam ser estimulados o associar, criar e encadear de ritmos e formas, por meio da leitura e da escrita, sejam individuais ou coletivas. Numa oficina de fotografia, poder-se-ia, dentre outras atividades, discutir e analisar os critérios de seleção de fotos, elaborar ensaios fotográficos a partir de poesias e textos, fotografar a partir de contrastes entre branco e preto, morte e vida, riqueza e pobreza, etc. Nas oficinas de teatro ou cinema, seria permitido sentir, imaginar, combinar, expressar, selecionar, tecer possibilidades, enfim. Em uma oficina de música o professor poderia desempenhar o importante papel de construção dos vínculos com a comunicação musical, propiciando aos alunos experiências criativas, auditivas e perceptivas com a música. Aqui, ressaltamos o aspecto expressivo da música e marcamos sua função de expressão e comunicação da imaginação e de sentimentos. A oficina de música pode propiciar, ainda, experiências criativas de execução, desenvolvimento da capacidade de escutar, atenção concentrada e compreensão auditiva.

Algumas questões importantes podem ser formuladas a partir da nossa proposta de prática centrada principalmente em oficinas. Poderíamos nos perguntar se as sugestões didático-pedagógicas para inserção das dimensões estética e expressiva no currículo, no cotidiano da escola, seriam limitadas a oficinas. Qual a relação com as demais áreas do conhecimento? Como se pensar a articulação dessas dimensões do ensino de arte com as demais áreas? A simples realização dessas oficinas provocaria mudanças significativas no ensino e na aprendizagem?

Pensamos que confinar a experiência estética a um momento e espaço escolar é um reducionismo. Defendemos que as relações interpessoais podem ser estéticas. Principalmente quando são relações de respeito ao outro, ao que é diferente de mim, quando consideramos a multiplicidade de formas de ver, sentir e compreender o mundo.

Trazer a estética para o cotidiano escolar é respeitar a diferença entre as pessoas. É a defesa da multiplicidade das possibilidades de sentir e expressar. É o reconhecimento da multiplicidade da espécie humana. É, também, o acolhimento das singularidades e o aprendizado da convivência com outros olhares sobre o mundo.

A proposta de desenvolvimento de atividades em oficinas pode ser uma alternativa, dentre outras, de integração entre as diversas disciplinas do currículo escolar, mesmo porque partimos de uma concepção de que as atividades artísticas compreendem capacidades, experiências e conhecimentos que são adquiridos nas vivências cotidianas e na apropriação das culturas informal e formal, como a educação escolar, por exemplo.

Compreende-se que a valorização que o aluno faz de uma atividade depende do significado pessoal e social dessa atividade, em que os motivos das experiências anteriores desempenham papel importante. Pretende-se, assim, desmistificar a idéia de que o processo criativo seja resultado de "talento", "inspiração", "gênio" ou outras expressões que por muito tempo alimentaram e sustentaram a visão de que existem alunos criativos e alunos que não são criativos. A contraposição a esse sistema de valores dominante se realiza quando compreendemos o papel da imaginação e da criação como processo que supõe preparação, trabalho e, principalmente, a inserção das artes no universo cotidiano dos alunos.

\section{CONSIDERAÇÕES FINAIS}

Neste momento o professor poderia se perguntar: Como formar leitores com professores não-leitores? Como escutar as fantasias de crianças, adolescentes e jovens se embotamos nosso próprio imaginário? Como estimular a criatividade, o raciocínio, a ousadia, se estamos tomados pela apatia? Como desenvolver a sensibilidade do estudante se a nossa própria sensibilidade é descuidada?

Desejamos romper este círculo vicioso que perpetua e justifica a reprodução de imobilismos, e acreditamos que o rompimento começa quando o professor muda sua atitude e destitui-se de sua posição de autoridade que detém o saber e transforma o aluno em mero receptador do seu saber. Quando o professor se coloca na relação do ensinar-aprender, aberto para o aprender-ensinando, ele pode romper essa reprodução. O fazer-junto-com-o-aluno o coloca na possibilidade de experimentar outras formas de relações em que o exercício da criatividade torna-se possível, em que a sensibilidade do aluno e do professor se constrói nas interações de sujeitos concretos, totais e humanos; de sujeitos não cindidos pelas relações autoritárias ainda dominantes nas escolas, que superdimensionam o racional e negam o sensível e o criativo como dimensões fundamentais para a constituição de sujeitos autônomos.

\section{REFERÊNCIAS}

Arnheim, R. (1969). Visual thinking. Berkeley: University of California. 
Barbosa, A. M. (1994). A imagem do ensino da arte. São Paulo: Perspectiva.

Barbosa, A. M. (Org.). (2002). Inquietações e Mudanças no Ensino da Arte. São Paulo: Cortez.

Deleuze, G. \& Guatarri, F. (1992). O que é filosofia. Rio de Janeiro: 34.

Duarte Jr., J. F. (1994). Fundamentos Estéticos da Educação. Campinas: Papirus.

Duarte Jr., J. F. (2001). O sentido dos sentidos. Curitiba: Criar Edições.

Duborgel, B. (1992). Imaginário e pedagogia. Lisboa: Instituto Piaget.

Durant, G. (1664). L' imagination symbolique. Paris: PUF.

Gagliardi, P. (1990). Symbols and artifacts: Views of the corporaet landscape. Berlin: Walter de Gruyter.

Goodman, N. (1995). De la mente y otras matérias. Madrid: Visor.

Habermas, J. (1987). Conhecimento e interesse. Rio de Janeiro: Guanabara.

Leontiev, A. (1978). Actividad, conciencia y personalidad. Buenos Aires: Ciências Del Hombre.

Machado, R. (1994). AHC ED ASAC: uma reflexão sobre a função da arte no magistério. Em A. M. Barbosa (Org.), A imagem do ensino da arte (pp. 20-32). São Paulo: Perspectiva.

Musil, R. (1989). O homem sem qualidades. Rio de Janeiro: Nova Fronteira.
Paz, O. (1977). El labirinto de la soledad. México: Fondo de Cultura Económica.

Paez, D. \& Adrián, J. (1993). Arte, lenguaje y emoción. Madrid: Fundamentos.

Rimé, B. (1993). Le partage social des émotions. En B. Rimé \& K. Scherer (Eds.), Textes de base em psycholigie: Les emotions (pp. 271-301). Neuchâtel/Paris: Delachaux \& Niestlé.

Sanches Vasquez, A. (1999). Convite à estética. Rio de Janeiro: Civilização Brasileira.

Sanches Vasquez, A. (1978). As idéias estéticas de Marx. Rio de Janeiro: Paz e Terra.

Zanella, A. V., Da Ros, S. Z., França, K. B. \& Reis, A. C. (2004). Mediação pedagógica: reflexões sobre o olhar estético em contexto de escolarização formal. Psicologia: Reflexão \& Crítica, 17(1), 51-60.

Vigotski, L. S. (1990). La imaginación y el arte en la infancia. Madrid: AKAL.

Vigotski, L. S. (2001). Psicologia pedagógica. São Paulo: Martins Fontes.

Recebido em 27/07/2007 Aceito em 14/09/2007

Endereço para correspondência : Denise de Camargo. Raposo Tavares, 5332, CEP 82100-000, Curitiba Paraná. E-mail: denisedecamargo@uol.com.br 